investigation of roquirements. Also, such matters as methods of test could easily be undertaken by joint user co-operation. If this co-operation. wore further extended and the users could be persuaded to do more research on requirements, it would then be possible to bully suppliers more sucoessfully, and obligo them to provide new materials with properties which were really needed.

Some discussion ensued on the differences between the devolopment of a now material and a now product. In the former case the dovelopment was usually for a specific purpose, whereas in the latter, having made the development, it was often necessary to search for a market. There were dangers attending on the change of manufacturing processos from, say, batch to continuous operation, since the product often possessed different properties, and it had been found in the past necessary in some cases to start from different raw materials.
Somo surprise was expressed at the lack of satisfactory composite materials, and this was attributed to the fact that scientific method had only recently been devoted to the development of composite materials. These were very often very expensive in the early stages and also the techniques were often tims consuming. However, it was folt that considorable advances in composite materials would occur over the next few years.

It is impossible to surn up in a few words a conference which covered such a wide field of materials and ideas, but a point which emerged very strongly - and which was commented on by a number of speakers - was the very keen interest displayed by lecturers and contributors to the discussion alike in economic matters. Even during a discussion on what the organizers felt would be purcly technical matters, the conference was continually being reminded of the noed to consider economies.

W. A. Holmes-Warkik

\title{
IDENTIFICATION OF ELUTED COMPONENTS IN GAS CHROMATOGRAPHY
}

$\mathrm{A}^{\mathrm{N}}$ informal symposium with "Identification of Eluted Components" as the main thome was held by the Gas Chromatography Discussion Group of the Iustitute of Petroleum on September 23, 1965, at the Bodington Hall residence of the University of Locds. The members were officially welcomed to the University by Prof. H. M. N. H. Irving.

The first paper, presented by Dr. R. P. W. Scolt (Unilever Research Taboratories, Colworth House), summarized recent work on the devolopment of a chromatograph that would oporate intermittontly, allowing a 15 min time interval to elepso after the elution of each poak.

Exporience in the separation of complex mixtures had shown that simultanoous low-resolution mass and infra. red spectra were needod to assign identities unequivocully to poaks. This being so, a singlo chromatographic mn extonding to as long as $24 \mathrm{~h}$ with each eluted component being given tho attention it deserved could result ultimately in a net gain in analysis tirne, particularly if compared with duplicate runs, one for high-spoed low-resolution mass speotrometry and the other for trapping and regeneration of samples for infra-red examination. Tailoring the gas ohromatographic and infra-red equipment to meet the proferred approach was the subject of the prosentation.

Because of the time nended to make a normal infra-red scan, it was essontial to be able to stop the chromatographic run for a 15-min per iod without adversely affecting tho chromatographic resolution of components still in the column. This was found to be possible using a set soquence of stopping the carrier gas flow at the exit of the column, directly after trapping out a peak and reloasing the column pressure at the inlet. Elution was re-started whon required by oponing the inlet and outlet valves and re-npplying the column pressure evenly ovor a period of about $30 \mathrm{sec}$. This proceduro has found extended applica. bility for the analysis of flavours using a 60 -ft. packed column having a performance of 30,000 theoretical plates.

To obtain the desired mass of component in the infre-red cell a concontration step was required; this has been achicved by condensing each fraction on to a $10-\mathrm{cm}$ column packed with 40 per cent 'Carbowax $200 \mathrm{M}$ ' a.t ambient temporature, from which it is automatically elutod rapidly at high temperature into tho infra-red cell. A sixty-fold concentration is possible by this means. Simultaneously with the infra-red exumination, a mass spectrum would also bo obtained using a low-resolution mass spectrometer, such os ' $M . S .10$ ', which would give similar resolution to the normal fast-sosn mass spoctro. metors but at less than one-fifth of the cost. For infra-red spectra, a norrnal ' $S P .200$ ' infra-red spectrophotometer with a 15-rnin scun has been used for which 25 ug of samplo was adequato, provided the cell was designed so that the sample was situated wholly in the light path. A suitable heated cell, plated internally to minimize adsorption of sample and with a total volume of $25 \mathrm{ml}$, was doseribed and the delermination of the spentrum of eugenol which has a vapour pressure of $30 \mathrm{~mm}$ at the cell temperature of $150^{\circ} \mathrm{C}$ was cited as an example of its use.

The wholo sequence of events has boon automated to such an extent that injection of the samplo in the first instance is the only manual oporation required.

The next paper, presented by Mr. L. Davies ('Shell' Research, Lid., Woodstock Agricultural Research Centre, Sittingbourne), dealt with the problems of identification encountered in the determination of pesticide residues in crops, soils, etc., where the solvent oxtract ean often contain very much loss than 1 p.p.m. of pesticide together with largo amounte of co-extracted material.

The electron capture ionization detector, which pcssessed selective responsc to certain halogenated compounds at levels below $10^{-3} \mathrm{~g}$, had been used succossfully with both planar and radial arrangements of anode to cuthode using a d.c. mode of operation with oxygen-free nitrogen as carrier; undesirable ionization offocts had been observed when using argon. The halogen sensitive leak dotector in its several forms (Associated Electrical Industries, Lid.) was also useful as a gas chromatographic detector at the nanogram. lovol although to achieve this sonsitivity with acceptable base-line stability tho electrode potential required optimizing and the cell (typos $H A$ and J had been usod) should be oporated in a stream of nitrogon. The electron capture and leak dotectors were used to complement each other, in so far as when tied in series they exhibited differing relative responses to certain halo. gonated compounds. This enabled some dogree of certainty to be attached to identification and considerably reduced the possibility of mistaking a product of low olectron affinity present in gross amounts for a trace of chlorinated compounds, as was possible when electron capture was used alone. Chromatograms illustrating this type of application were shown. While the linearity of response of the leak detector cell was about three times that of electron capture and the elements are inexpensive, a degree of eloctrical instability and the need for conditioning are features that have to be contended with. Mr. Davies pointed out, however, that the cells were being used for an application for which they were not dosigned.

For non-halogenated orgmo-phosphorus pesticides it sodium thermionio detector, adapted from a flams ionization detector by fusing sodium sulphate to a platinum wire colloctor electrode, had been the subject of investiga. 
tion. A response to nanogram quantities of organophosphate pesticide had been obtained by increasing the electrode temperature but this had resulted in rapid loss of selectivity and base-line stability; similar characteristics were found when other alkali metal salts were used and when the salt was introduced into the flame at various positions. Some reduction in the rapid loss of selectivity at high-sensitivity settings had been obtained by using a tube of thin platinum $1 \mathrm{~mm}$ in diameter filled with sodium sulphate as the 'pick-up' electrode. There was considerable scope for development of this detector and the leak detector for use as selective detectors in gas chromatography.

Using the chromatograms obtained for a mixture of $n$-alkane, iso-alkane and alicyclic hydrocarbons, Dr. D. R. Deans (Imperial Chemical Industries, Ltd., Heavy Organic Chemicals Division, Billingham), in the third paper presonted, showed that superior separation of certain compononts difficult to separate could be obtained by using two columns of different type in series and backflushing part of the sample through the first column at some eritical stage during the elution. The degree of separation which could be achieved was better than could be obtained by straightforward elution through either of the columns used alone or in series. In addition to this novel applica. tion of backflushing there was also its more conventional use in conjunction with pre-columns for isolating heavy components. Despite these applications, the technique was not widely used and Dr. Deans thought this was due to the mechanical difficulties of operating taps enclosed in ovens and the attendent contamination of sample with grease and increase in dead volume causing band spreading. These objections had been overcome by using a system in which a capillary $T$-junction was used to connect the two series columns with one $\lim b$ of the junction extending outside the oven to the control system. Similarly the controls for injection and backflush vent were outside the oven (for details see $J$. Chromatog., 18, 477; 1965).

The combinations of columns (two packed, two capillary or packed and capillary in series), of liquid-phase type on the columns, of cutting and of treating the backflush (to vent or back to the column system) were innumerable. Fractions or compounds monitored out of the stream at some intermediate stage could be subjected to in-line reaction using micro-reactors or pyrolysis units. A fascinating example of this type of application was described in which the identification of the components of a complex mixture of heptenes, for which pure compounds for use as references were not available, was achieved by hydrogenating monitored peaks and re-chromatographing them against the more readily available saturated hydrocarbon reference compounds. Operation of the various systems described was considered to be very simple in practice and a switching unit had been constructed for connexion to any existing chromatograph allowing all possible schemes of operation to be used.

Mr. M. B. Evans (Natural Rubber Producers' Research Association) described his work concerned with the role of the solid support in retention measurement. One aspect which had been investigated was the apparent increase in polarity of non-polar liquid phases when used under conditions where oxygen is not rigorously excluded from the column. The retention characteristics of $\mathrm{a}$ wide range of solute types on freshly prepared squalane columns to which known weights of high molecular weight alcohols, aldehydes and ketones had been added were compared with retentions on a squalane column which had been deliberately oxidized at $100^{\circ} \mathrm{C}$; for the columns with added oxygenated compounds there was evidence to show that retention indices are linearly dependent on oxygen content, whereas for oxidized columns there was an initial drop in retention for polar solutes (also a pronounced reduction in peak tailing) followed by an increase. It was suggested that the initial drop observed was due to the first formed strongly polar compounds deactivating the surface and the values at the minimum of the curve corresponded to the retention index due to true partitioning in the squalane.

Evaluation of a number of glycols as support deactivators led to the conclusion that diglycerol was most efficient and its use had enabled improvements in peak symmetry and reduced solute isomerization and decomposition. Detailed investigation of the effect of diglycerol-treated support on the retention of wealkly polar solutes by dinonyl phthalate and squalane phases showed retention to be almost independent of the ratio of liquid phase to the diglycerol deactivator; the retention of polar solutes such as alcohols was found to display marked dependence similar to that observed when squalane was oxidized.

It was considered feasible that the extent of the initial high retention of polar solutes when low liquid phase loadings were used could be a measure of the support activity. The evaluation of a wide range of support material using squalane as the liquid phase and a wide range of solutes at constant sample size provided convincing evidence that support activity could be measured in this manner and indicated that a commercially available silane-treated product was the least adsorptive of those investigated. It was also considered that an evaluation of the support could be made by the reversed procedure of assessing the extent of the deactivation of polar groups of the liquid phase by the support at constant proportion of liquid phase, thus the highest retention index for a polar solute should be given by the least active support. This was confirmed experimentally using polyethyiene glycol liquid phase on the same range of supports as were used for the other investigation.

The final paper of the symposium was presented by Dr. J. F. K. Huber (University of Amsterdam) under the title "Two-Dimensional Gas Chromatography". He discussed factors relevant to the identification of components using two columns having different liquid phases as coatings. After listing the various forms of retention by which a solute could be characterized, Dr. Huber examined in some detail the factors affecting the accuracy of such data, among which were effects due to interfaces, pressure, flow changes and non-linearity of the partition isotherm. The results obtained by sample injection into two different types of column could be correlated by com. bining relative peak area values and known retention values although one source of error was the presence of masked peaks. With two columns combined so that fractions of the effluent from the first column were injected into the second column more definite results could be obtained as well as enrichment of a trace relative to a main component.

C. G. Scot'T

\section{URBAN TRAFFIC PROBLEMS}

\begin{abstract}
A MEMORANDUM issued by the Ministry of Transport/Scottish Development Department deals with the principles of applying traffic engineering techniques to urban road traffic problems*. It is designed to enable

* Ministry of Transport/Scottish Development Department. Advisory Memorandum on Orban Traffic Engineering Techniques. Pp. xi + 92. (London:
\end{abstract} H.M.S.O., 1965.) 78.6d. net. suitable short- to medium-term solutions to be found for urgent traffic problems, while providing a useful guide to the wide range of traffic engineering methods and techniques, many of which must be used in formulating the long-term traffic solutions which will be incorporated in comprehensive land use/transport plans. It does not attempt to give guidance on the surveys needed for 